\title{
MÍDIAS SOCIAIS EM TEMPOS DE BIBLIOTECAS 2.0: UM ESTUDO EM BIBLIOTECAS DAS INSTITUIÇÕES FEDERAIS DE ENSINO BRASILEIRAS TRAZENDO PERSPECTIVAS FUTURAS PARA A PRESERVAÇÃo digitaL
}

\author{
SOCIAL MEDIA IN THE ERA OF LIBRARIES 2.0: \\ A STUDY IN BRAZILIANS FEDERAL EDUCATION INSTITUITIONS' \\ LIBRARIES BRINGING FUTURE PERSPECTIVES FOR DIGITAL PRESERVATION \\ MEDIOS SOCIALES EN LA ERA DE LAS BIBLIOTECAS 2.0: \\ UN ESTUDIO EN BIBLIOTECAS DE INSTITUCIONES FEDERALES DE EDUCACIÓN BRASILEÑAS \\ TRAYENDO PERSPECTIVAS PARA LA PRESERVACIÓN DIGITAL
}

\section{Laura Vilela Rodrigues Rezende ${ }^{1}$ \\ Dalton Lopes Martins ${ }^{2}$ \\ Marcel Ferrante Silva ${ }^{3}$}

\begin{abstract}
RESUMO
O presente estudo pretende discorrer sobre os principais desafios no tocante à participação social na Web por parte das Bibliotecas Universitárias das Instituições Federais de Ensino (IFES) Brasileiras, bem como as transformações em relação à atuação destas instituições, especialmente as interações com seu público. A pesquisa realizou um levantamento de caráter quantitativo acerca do uso das principais mídias sociais existentes por parte das bibliotecas das IFES brasileiras. O levantamento buscou identificar o grau de envolvimento e participação dessas bibliotecas em mídias sociais. Entende-se que tal investigação se faz necessária como embasamento à urgente necessidade de sensibilização destas instituições brasileiras quanto ao valioso potencial de interação com seus usuários por meio destas mídias, apesar do estudo ter demonstrado um uso incipiente. Com base no levantamento realizado, o estudo traz uma reflexão acerca da importância que se deve dedicar à preservação digital, não somente dos seus acervos, mas também dos relevantes registros das relações estabelecidas entre as bibliotecas e seu público por meio das mídias sociais. Os resultados demonstram que a maioria das universidades públicas utilizam ferramentas Web $2.0 \mathrm{com}$ enfoque social, sendo a maior adoção do Facebook (43\%) e do Twitter (29\%), porém apenas 5\% delas usa esse meio de comunicação para fazer divulgação dos acervos. Dessa forma, foi possível concluir que o uso de mídias sociais por estas bibliotecas tem ainda muito a se desenvolver e consequentemente as ações de preservação digital precisam considerar a inclusão de conteúdos gerados por estas mídias que cada vez mais têm se tornado um valioso canal de comunicação.
\end{abstract}

PALAVRAS-ChAVE: Biblioteca universitária. Mídia social. Preservação digital.

\section{ABSTRACT}

This study aims to discuss the main challenges regarding the social participation on the Web by the Brazilian Federal Education Institutions'(IFES) Libraries and the changes related to the these institutions' activities, especially interactions with their audience. The Research conducted a quantitative approach survey on the use of the main existing social media by these libraries. The survey sought to identify the level of involvement and participation of these libraries in social media. It is understood that this investigation is necessary as a foundation to the urgent need to raise awareness these Brazilian institutions as the valuable potential of

\footnotetext{
${ }^{1}$ Doutora em Ciência da Informação (UnB). Docente da Universidade Federal de Goiás. Goiânia, GO. E-mail: lauravil.rr@gmail.com. - ORCID: http://orcid.org/0000-0002-8891-3263.

${ }^{2}$ Doutor em Ciência da Informação (USP). Docente da Universidade Federal de Goiás. Goiânia, GO. E-mail: dmartins@gmail.com. - ORCID: http://orcid.org/0000-0002-6244-6791.

${ }^{3}$ Doutor em Ciência da Informação (UFMG). Docente da Universidade Federal de Goiás. Goiânia, GO. E-mail: marcelf@gmail.com. - ORCID: http://orcid.org/0000-0001-7036-3905.
}

Submetido em: 31/07/2016 - Aceito em: 15/09/2016 
interaction with their users through these media, despite the study demonstrated an incipient use. Based on the conducted survey, the study presents a reflection of the importance that it should devote to digital preservation, not only of their collections, but also the relevant records of the social media content. The results show that most brazilian public universities use Web 2.0 tools with social focus, and the greater adoption of Facebook (43\%) and Twitter (29\%), but only $5 \%$ of them use these medias to disseminate the collections. Thus, it was concluded that the use of social media by these libraries still have a lot to develop and consequently the digital preservation actions need to consider the inclusion of content generated by these media that increasingly have become a valuable communication channel.

KEYWORDS: University library. Social media. Digital preservation.

\section{RESUMEN}

Este estudio tiene la intención de discutir los principales desafíos en cuanto a la participación social en la Web por las bibliotecas de las instituciones federales de educación brasileñas, así como los cambios en relación con las actividades de estas instituciones, especialmente la relación con su público. La investigación llevó a cabo una encuesta de enfoque cuantitativo en la utilización, por las bibliotecas de Instituciones Federales de Enseñanza Brasileñas (IFES), de las principales características interactivas digitales. El estudio trató de determinar el grado de implicación y participación de estas bibliotecas en las plataformas digitales interactivas. Este tipo de investigación es necesaria como base para la urgente necesidad de aumentar la conciencia de estas instituciones brasileñas acerca de la preservación digital, no sólo de sus colecciones, sino también los registros pertinentes de las relaciones que se establecen entre ellos y su audiencia a través de las herramientas Web 2.0. Los resultados muestran que la mayoría de las universidades públicas utilizan herramientas Web 2.0 con enfoque social, y la mayor adopción es de Facebook (43\%) y Twitter (29\%), pero sólo el 5\% de ellos utilizan este medio de comunicación para difundir las colecciones. Por lo tanto, el uso de las redes sociales por las bibliotecas de las universidades públicas tiene mucho que desarrollar.

PAlABRAS ClAVE: Biblioteca de la universidad. Medios sociales. Preservación digital.

\section{INTRODUÇÃO}

O desenvolvimento contínuo da Internet nas últimas décadas bem como a sofisticação de suas ferramentas de interação social tem trazido importantes reflexões para o mundo das bibliotecas. Desde a chegada de novos dispositivos tecnológicos que permitem maiores possibilidades de interação com seus usuários até a reflexão sobre novas formas de mediação da informação e novas maneiras de participação social desses usuários em processos de curadoria, atribuição de relevância e avaliação da informação, desafios significativos têm sido oferecidos tanto para a formação do bibliotecário quanto para seu fazer profissional cotidiano.

Os principais desafios se concentram no papel social que a biblioteca pode ocupar nesse novo cenário, como afirmam Jaeger, Bertot e Fleischman (2011, p. 7):

a Internet e suas tecnologias associadas também permitiram às bibliotecas a tomar papéis sociais impensáveis, tais como serviços de governo eletrônico e respostas emergentes a situações sociais em tempo real estando entre os dois dos mais proeminentes novos papéis sociais.

Ao mesmo tempo, são esses papéis sociais impensáveis que abrem grandes possibilidades para inovação em produtos e serviços informacionais, permitindo que as próprias bibliotecas produzam novas estratégias de relacionamento e envolvimento social com seus usuários. Um dos aspectos centrais dessas possibilidades de inovação que se pode

\begin{tabular}{l|l|l|l|l|l|l|l} 
(C) Rev. Digit.Bibliotecon. Cienc. Inf. & Campinas, SP & v.14 & n.3 & p.484-500 & set/dez. 2016 & ISSN 1678-765X \\
\hline
\end{tabular}


citar é a mudança cultural provocada pelo incremento no envolvimento dos usuários com esses novos produtos e serviços, ou seja, há aqui a constatação de um maior desejo e potencial de participação social, como apresenta Mon (2011, p. 67):

\begin{abstract}
Os sites da Web 2.0 tem proporcionado uma mudança cultural na expectativa de participação dos usuários nas interações informacionais online. Em sites interativos tais como Yahoo Respostas!, os usuários não apenas perguntam como também respondem as questões; na Wikipedia, usuários lêem as páginas para procurar informações e podem também reescrever essas páginas com novas informações. No entanto, as bibliotecas focaram numa relação social um-a-um de pergunta e resposta na qual os usuários perguntam e os bibliotecários respondem. Nos sites da Web 2.0, a relação proposta tem sido de um-para-muitos e muitos-para-muitos acionando uma cultura participativa de questionar e responder na qual qualquer um pode participar perguntando, respondendo ou mesmo contribuindo para uma resposta comunitária a uma questão.
\end{abstract}

Segundo Torres (2009), mídias sociais são páginas da Web que possibilitam ao usuário atuar não apenas como um mero leitor, e sim como produtor, curador e consumidor da informação, com a liberdade de criar, recomendar e trocar conteúdo com os outros usuários. Já uma rede social pode ser definida como um ambiente online no qual um usuário pode estabelecer relações com outros usuários que tenham alguma ligação e/ou interesse em comum. Assim, entende-se que o conceito de mídia social é mais amplo, uma vez que são "ferramentas online usadas para divulgar conteúdo ao mesmo tempo em que permitem alguma relação com outras pessoas" (ALTERMANN, 2009). Dessa forma, redes sociais e blogs podem ser considerados como tipos de mídia social ou podem ser usados como uma mídia social. Para este estudo, optou-se por utilizar o conceito de mídia social devido a sua amplitude se comparado à definição de rede social.

O termo Web 2.0 foi utilizado pela primeira vez por DiNucci em 1999, embora o uso do termo naquela ocasião não fizesse referência exatamente ao seu uso atual. DiNucci (1999, p. 32, tradução nossa) escreveu:

A web que conhecemos agora, que é carregada em uma janela do navegador com recursos essencialmente estáticos é apenas um embrião da web que está por vir. Os primeiros vislumbres da Web 2.0 estão começando a aparecer, e nós estamos apenas começando a ver como esse recurso embrionário poderá se desenvolver.

O termo Web 2.0 foi reintroduzido em sua utilização atual por Tim O'Reilly, fundador da O'Reilly Media. Ele apresentou as definições originais de Web 2.0 além de citar seus sete princípios:

web como plataforma; incentivo à inteligência coletiva; flexibilidade no controle de dados, podendo ser feito pelos próprios usuários; softwares deixam de ser produtos e passam a ser pacotes de serviços; modelos de programação de software confiáveis para aplicações distribuídas; software acima do nível de dispositivo único; experiências enriquecedoras dos usuários. (O'Reilly, 2005, tradução nossa). 
Web 2.0 refere-se à segunda geração da Web projetada para facilitar as relações sociais, o compartilhamento da informação, a interoperabilidade e a comunicação (Tripathi and Kumar, 2010, p.195, tradução nossa).

Pode-se definir Web 2.0 como sendo o conjunto de novas tecnologias e padrões para desenvolvimento de páginas interativas na Internet que disponibilizam recursos para que os usuários possam publicar conteúdos e interagir, como por exemplo, curtir, compartilhar, comentar, com objetos dessas páginas. A capacidade de compreender essa mudança cultural como o exercício de novas possibilidades de papéis sociais que a biblioteca pode exercitar, permite que ela se reposicione e experimente novos modos de relacionamento social com seus usuários. Um dos meios pelos quais essa experimentação pode ocorrer é a adoção de ferramentas Web 2.0, principalmente as mídias sociais.

Em um importante estudo publicado pela American Library Association Woodward (2013, p. xii) está presente a afirmativa de que as bibliotecas nos Estados Unidos da América não aproveitaram as potencialidades das mídias sociais, argumentando que ao retomarem sua trajetória comparando os serviços que deram certo e aqueles que deram errado, o fator mais importante a ser considerado é a capacidade de conhecimento da natureza humana na concepção desses serviços. Dessa maneira, o que se deveria considerar é a capacidade de compreender a natureza comunicacional e informacional do uso humano dessas mídias sociais que pode, segundo a autora, potencializar a criação de inovações na relação da biblioteca com seus usuários.

Um estudo publicado por Kane (2011, p. 04) sobre as responsabilidades da biblioteca, afirma que é necessário se avaliar uma mudança importante de postura, onde de uma posição de aguardar a demanda chegar pelo usuário, o bibliotecário passa a procurar ativamente a relação social, estabelecendo novas formas de conexão com esse usuário, novos tipos de serviços de referência virtuais e novas formas de divulgação das coleções existentes na biblioteca. Accart (2012, p. 164) menciona que o sucesso desses novos serviços de referência virtuais se deve à nova dimensão que os mesmos encontram nas redes virtuais de informação, facilitando seu acesso e permitindo um maior grau de personalização na construção de sua demanda.

O termo "Biblioteca 2.0" pode ser definido como a abreviação de uma vasta gama de iniciativas em todos os tipos de bibliotecas que visam incorporar as ferramentas de colaboração on-line para novas formas de fornecer serviços informacionais eficazes (AMERICAN LIBRARY ASSOCIATION, 2016, tradução nossa).

Casey e Savastinuk afirmam que a Biblioteca 2.0 deve estar centrada no usuário e caracterizam: "É um modelo para o serviço de biblioteca que encoraja a mudança constante e intencional, convidando o usuário a participar da criação tanto de serviços físicos quanto de virtuais conforme sua vontade, apoiado por consistentes serviços de avaliações" (Casey e Savastinuk, 2006, p.40, tradução nossa). 
Outra faceta, e vale dizer que não menos importante, desses desafios de uso das mídias sociais pelas bibliotecas é a compreensão de que essas mídias também possuem um lado documental, ou seja, elas não apenas produzem espaços de sociabilidade em rede e meios de relacionamento social entre bibliotecários e seus usuários, como também produzem registros de informação que se tornam importantes fontes de informação para pesquisa e análise da própria sociedade no século XXI. Aqui se apresenta outro desafio que é o da preservação digital e a capacidade de se produzir serviços que considerem as mídias sociais como fontes legítimas de informação, facilitando o acesso a essas bases de dados de maneira amigável e acessível.

A Association for Library Collections and Technical Services (2016, tradução nossa) traz um conceito de preservação digital que vai além das questões puramente tecnológicas:

A preservação digital combina políticas, estratégias e ações que garantem acesso a conteúdos nativos digitais ou digitalizados independentemente dos desafios relacionados a falhas de arquivos, mídias ou mudanças tecnológicas. Visa garantir autenticidade do documento ao longo do tempo.

Ferreira (2006, p.20) confirma esta visão holística afirmando que a preservação digital pode ser entendida como o conjunto de atividades ou processos responsáveis por garantir o acesso continuado a longo-prazo à informação e patrimônio cultural existentes em formatos digitais.

Neste sentido, o foco da preservação digital se distancia cada vez mais da necessidade de se tomar medidas imediatas para "recuperar" materiais ameaçados priorizando a percepção de que perpetuar materiais digitais em longo prazo envolve a observância de práticas cuidadosas de gestão de ativos digitais que perpassam todo o ciclo de vida da informação. Isto por sua vez, nos obriga a olhar para a preservação digital não apenas como um mecanismo que visa garantir que sequências de bits criados hoje serão acessadas e recuperadas amanhã, mas como um processo que opera em conjunto com uma gama de serviços que suportam ambientes informacionais digitais, além de tratar aspectos relacionados à economia global, tais como os contextos legais e sociais (LAVOIE; DEMPSEY, 2004, p.20, tradução nossa).

Diante deste desafio de se discutir a preservação digital no contexto das mídias sociais é possível afirmar que ainda existem poucas experiências de bibliotecas que se preocupam em produzir serviços nessa direção, porém vale citar aqui uma matéria intitulada "British Library adds billions of webpages and tweets to archive" do The Guardian (MEIKLE, 2013), relevante e renomado jornal britânico, que cita a iniciativa da British Library de arquivar páginas Web e postagens na mídia social Twitter de políticos e importantes personalidades públicas do Reino Unido. É possível perceber aqui um conjunto de materiais baseados em documentos até então inexistentes como fontes tradicionais de informação para as bibliotecas. 
Iniciativas como essa revelam não apenas a importância que as mídias sociais passam a adquirir no cenário contemporâneo, mas também a necessidade de reflexão por parte do profissional da informação sobre que valores essa forma de sociabilidade em rede vem trazendo para o universo dos produtos e serviços informacionais.

É a partir desse cenário inicial, onde se tem de um lado a necessidade da produção de novas experiências de participação social dos usuários na relação com as bibliotecas por meio das mídias sociais e do outro, a necessidade emergente de estratégias de preservação digital que contemplem esses novos tipos de documentos produzidos, que se apresenta essa pesquisa cujo questionamento está pautado na problemática de identificar e avaliar como as bibliotecas brasileiras estão utilizando as mídias sociais de maneira geral para então, propor uma reflexão sobre a importância da implementação de ações de preservação digital dessas fontes de informação por parte dessas bibliotecas.

A próxima seção apresenta a metodologia utilizada para a realização da pesquisa, incluindo como a amostra de bibliotecas foi definida, sua presença na Internet, especialmente nas mídias sociais e quais critérios foram considerados para se qualificar o uso dessas mídias por parte dessas bibliotecas. Na seção seguinte de Resultados, apresentam-se os dados coletados de forma descritiva procurando identificar algumas tendências sugerindo algumas possibilidades de interpretação. Por fim, na seção Considerações Finais, apresentam-se algumas conclusões e, sobretudo, como se pretende aprofundar futuramente esse estudo para um âmbito maior de bibliotecas no cenário brasileiro.

\section{MÉTODO}

Considera-se que esta pesquisa possui enfoque quantitativo uma vez que o processo investigativo foi sequencial e comprobatório. Parte-se de uma ideia que vai sendo delimitada e, uma vez definida, se extraem os objetivos e perguntas de pesquisa, revisa-se a literatura e constrói-se o marco ou perspectiva teórica. Em suma, este enfoque se utiliza da coleta de dados baseando-se na medição numérica e na análise estatística para estabelecer padrões e comprovar teorias.

Por meio de um indicador de qualidade que avalia as instituições brasileiras de educação superior, o Índice Geral de Cursos Avaliados da Instituição - IGC, última versão de 2014, produzido pelo Instituto Nacional de Estudos e Pesquisas Educacionais Anísio Teixeira (INEP, 2016) ${ }^{4}$, foi possível definir a amostra a ser investigada, 61 Instituições Federais de Ensino Superior (IFES). Deste total, constatou-se que 56 delas utilizam mídias sociais.

Entende-se que a amostra composta por Instituições Federais de Ensino Superior abrange geograficamente todo o país sendo possível ter uma visão ampla da utilização de

${ }^{4}$ Disponível em : http://portal.inep.gov.br/educacao-superior/indicadores/indice-geral-de-cursos-igc 
ferramentas Web 2.0 por parte das bibliotecas universitárias de instituições que fazem parte da mesma esfera pública. Ressalta-se aqui que uma vez que os Institutos Federais de Ensino são instituições que atuam basicamente na oferta da educação profissional e tecnológica, em todos os seus níveis e modalidades (MEC, 2016), e devido ao seu elevado quantitativo, optou-se por não incluir esta modalidade na amostra da pesquisa.

Inicialmente, buscou-se definir o conteúdo que seria investigado referente ao uso de ferramentas Web 2.0 no cenário das bibliotecas brasileiras. Pretende-se identificar e caracterizar as bibliotecas universitárias das IFES brasileiras que utilizam mídias sociais, quais as mídias utilizadas, suas audiências, tipos de conteúdos e periodicidade das postagens considerando seu tempo de existência. Os dados coletados pelos pesquisadores deste estudo foram extraídos das próprias mídias sociais das bibliotecas da amostra. Ao final, utilizou-se a ferramenta de questionários "Formulários Google" para organizar e tabular os dados coletados.

\section{RESULTADOS}

A seguir são apresentados os resultados deste estudo visando delinear o cenário do uso de ferramentas Web 2.0 pelas Bibliotecas das IFES brasileiras.
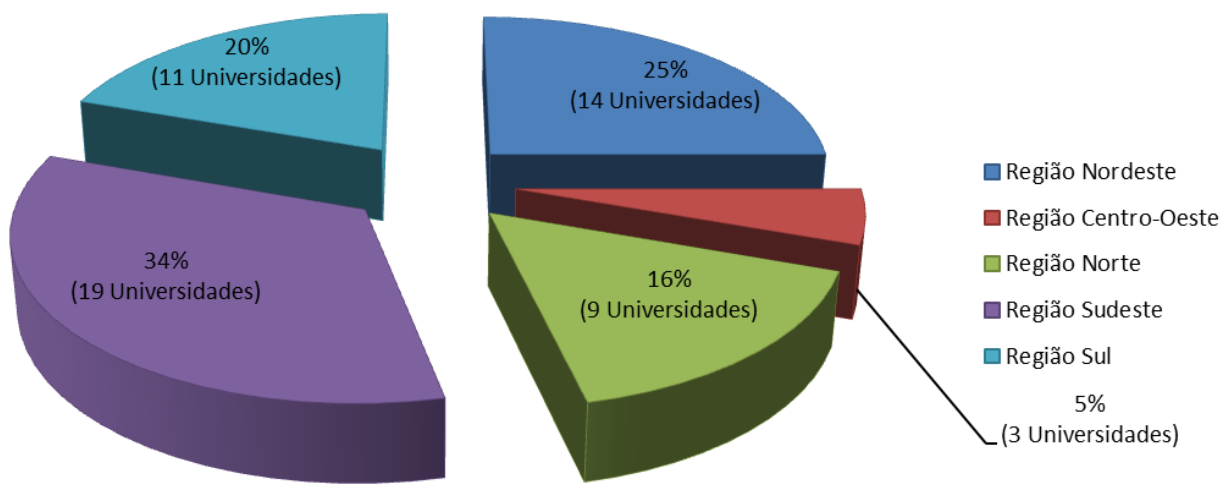

Gráfico 1. Bibliotecas Universitárias das IFES Brasileiras que utilizam ferramentas Web 2.0 por região geográfica

Fonte: os autores

O destaque no gráfico 1 é para as participações expressivas de todas as regiões brasileiras no tocante à utilização de ferramentas Web 2.0, de maneira geral. As bibliotecas universitárias de todas as IFES das cinco regiões brasileiras utilizam ferramentas Web 2.0.

${ }^{5}$ Disponível em: <http://www.google.com/intl/pt-BR/forms/about/>. 
Sugere-se que tal cenário demonstra uma preocupação de interação com os usuários via mídias sociais por parte destas unidades de informação, embora os próximos gráficos sinalizem que esta utilização ainda ocorre de forma incipiente e superficial.

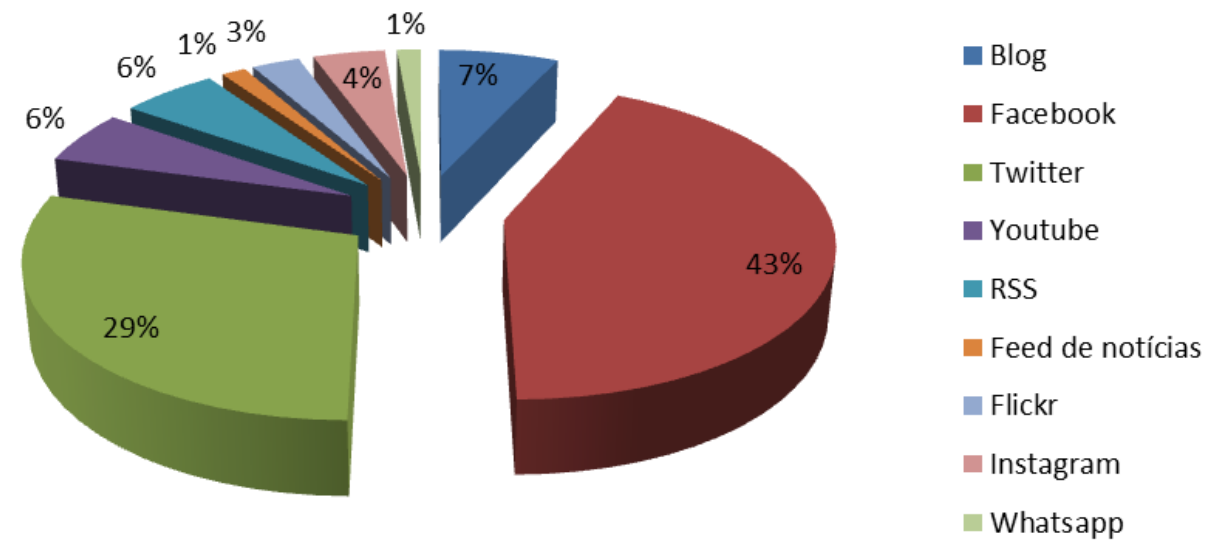

Gráfico 2. Ferramentas Web 2.0 utilizadas pelas bibliotecas universitárias das IFES brasileiras

Fonte: os autores

O gráfico 2 apresenta quais as ferramentas Web 2.0 utilizadas pelas bibliotecas universitárias das IFES brasileiras. A maioria das bibliotecas utiliza Facebook e Twitter. Destaca-se que o somatório da utilização dessas duas ferramentas totaliza $72 \%$ do total de bibliotecas. Tal número pode ser justificado pela facilidade de uso e a audiência entre os jovens.
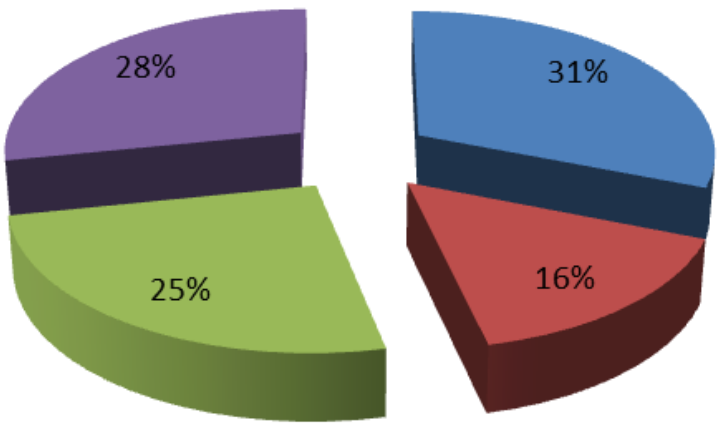

Até 100 seguidores

- De 101 a 500 seguidores

De 501 a 1500 seguidores

Mais de 1500 seguidores

Gráfico 3. Audiência das ferramentas Web 2.0 utilizadas nas bibliotecas universitárias das IFES brasileiras

Fonte: os autores

A audiência das ferramentas Web 2.0 utilizadas pelas bibliotecas das IFES brasileiras pode ser representada no gráfico 3. A maior fatia foi de $31 \%$ das bibliotecas que possuem até cem (100) seguidores. Este número representa em valor aproximado, a fatia das bibliotecas 
que afirmaram, conforme gráfico 2 possuir as mídias sociais: Youtube, RSS, Feed de notícias, Flickr, Instagram e Whatsapp. Ressalta-se que neste quantitativo não estão incluídas as mídias sociais: Facebook, Twitter e Blog. Por outro lado, 28\% das bibliotecas afirmaram possuir mais de 1500 seguidores. Este último número está relacionado com a participação das bibliotecas no Facebook e twitter, mídias sociais que conseguem obter um alcance significativo.
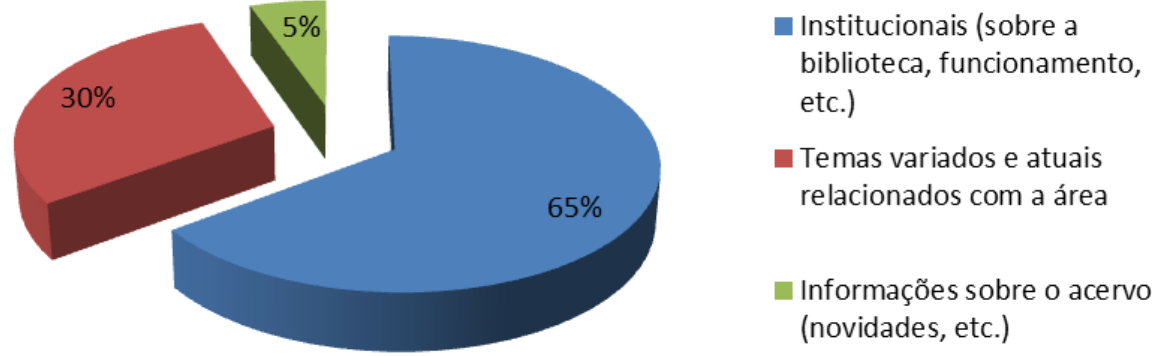

Gráfico 4. Tipos de informações postadas nas ferramentas Web 2.0 das bibliotecas universitárias das IFES brasileiras

Fonte: os autores

Em relação aos tipos de informações postadas nas ferramentas Web 2.0 das bibliotecas universitárias das IFES brasileiras, vale destacar no gráfico 4 que $65 \%$ das bibliotecas se utilizam das mídias sociais para postar informações institucionais. Uma vez que somente $5 \%$ das bibliotecas postam informações sobre o acervo, é possível afirmar que, além da ausência de planejamento voltado para a utilização de ferramentas colaborativas, não existe uma interligação entre a divulgação do conteúdo dos acervos e as mídias sociais. Esta situação pode também sinalizar que as soluções tecnológicas de bibliotecas digitais e gestão de acervos em geral utilizadas pelas bibliotecas brasileiras não interagem com as ferramentas Web 2.0. Tal desvinculação faz com que o conteúdo existente nas mídias sociais dessas bibliotecas não se relacione com a circulação dos acervos existentes. 


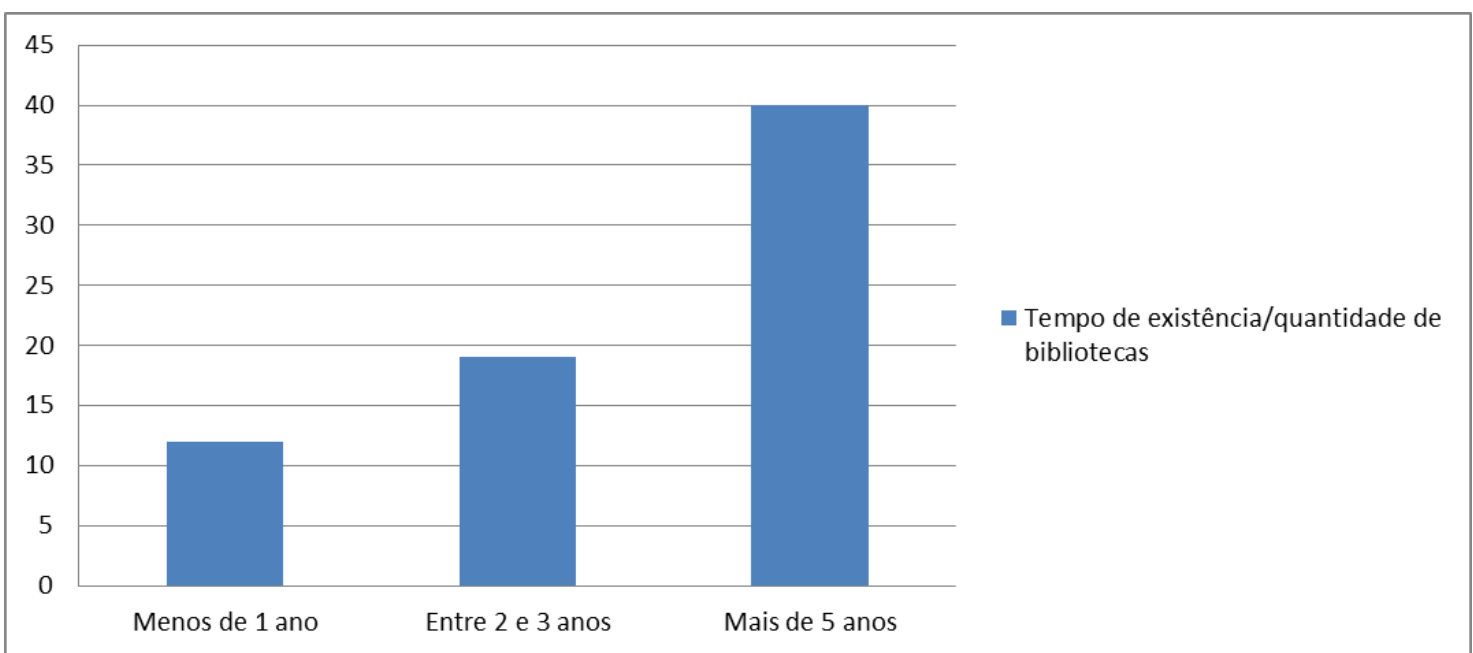

Gráfico 5. Tempo de existência das ferramentas Web 2.0 das bibliotecas universitárias das IFES brasileiras

Fonte: os autores

O gráfico 5 apresenta os dados referentes ao tempo de existência das ferramentas $W e b$ 2.0 das bibliotecas universitárias das IFES brasileiras. A maioria das ferramentas dessas bibliotecas foi criada há mais de cinco (5) anos. Tal cenário demonstra o interesse destas bibliotecas universitárias em participar de ferramentas colaborativas na Web já há algum tempo, embora os dados do gráfico anterior tenham demonstrado que os conteúdos presentes necessitam ser diversificados especialmente no que se refere à divulgação de seus acervos.

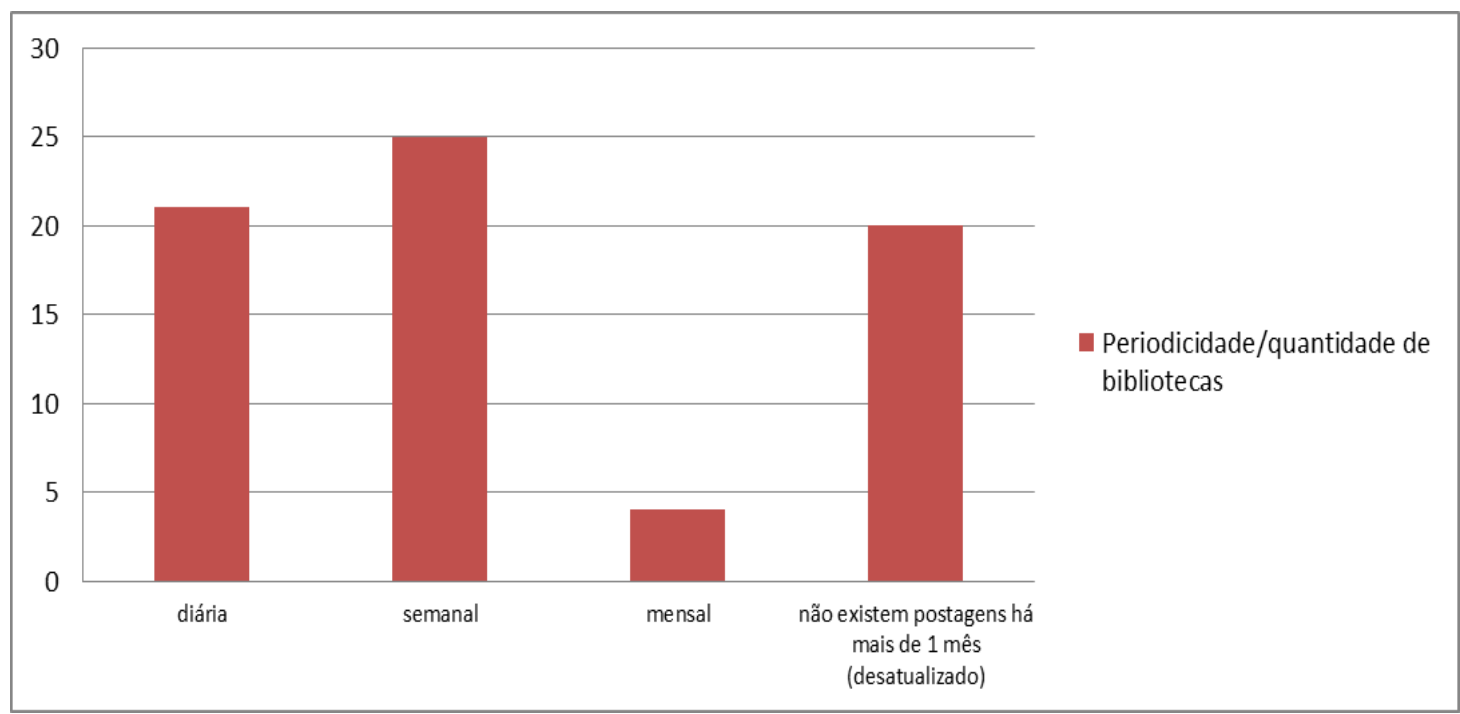

Gráfico 6. Periodicidade das postagens nas ferramentas Web 2.0 das bibliotecas universitárias das IFES brasileiras

Fonte: os autores 
No tocante à periodicidade das postagens nas ferramentas Web 2.0 das bibliotecas universitárias das IFES brasileiras, pode-se afirmar, com base no gráfico 5 que as postagens diárias e semanais aparecem em maior quantidade, justificando-se pela presença expressiva dessas bibliotecas no Facebook e Twitter, . As outras ferramentas (Youtube, RSS, Feed de notícias, Flickr, Instagram e Whatsapp), de maneira geral estão desatualizadas com postagens em intervalos de mais de um (1) mês. Tal situação pode sinalizar mais uma vez a preocupação destas bibliotecas em atuar de forma colaborativa na Web 2.0 interagindo com seus usuários, porém sem um planejamento efetivo de presença nas mídias sociais visando incrementar a periodicidade e diversificar o conteúdo das postagens.

\section{Perspectivas futuras para a preservação digital de mídias SOCIAIS EM TEMPOS DE BIBLIOTECAS 2.0}

Os resultados apresentados demonstram que o uso de ferramentas Web 2.0 por parte das bibliotecas universitárias das IFES é expressivo e abrange mídias sociais variadas. Este cenário direciona o questionamento inicial da presente pesquisa para a urgência de se iniciarem discussões ao nível nacional sobre como preservar este tipo de conteúdo uma vez que se trata de um imenso volume informacional, conteúdo relevante, crescimento exponencial e que abrange um número significativo de usuários destas unidades de informação. Estas discussões se fazem necessárias uma vez que as ações de preservação digital atuais nas bibliotecas, ainda que incipientes, de maneira geral priorizam os conteúdos dos acervos.

Para contextualizar o cenário de ações de preservação digital brasileiras, o gráfico 7 a seguir, extraído do Directory of Open Access Repositories (2016), demonstra que do total de repositórios digitais brasileiros registrados nesta base, 82,4\% não possuem políticas de preservação digital definidas. $\mathrm{O}$ estado "Unstated" representa os repositórios que se referem à política de preservação digital, porém ela não foi localizada. O estado "Unknown" representa os casos em que nenhuma referência à política de preservação digital foi localizada no repositório. Somando-se os estados de "Undefined" e "Unknown", totaliza-se 89,2\% de repositórios indexados neste diretório que não possuem política de preservação digital. 


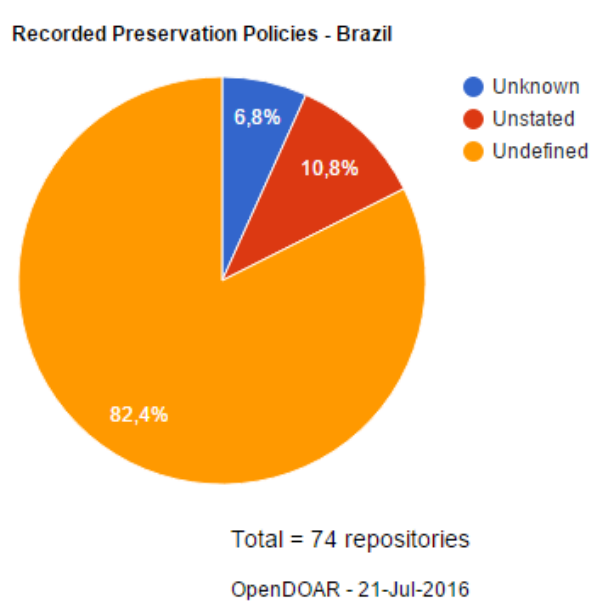

Gráfico 7. Políticas de Preservação Digital Registradas no Brasil

Fonte: Directory of Open Access Repositories: Disponível em:

$<\mathrm{http} / /$ www.opendoar.org/onechart.php?cID=31\&ctID=\&rtID=\&clID=\&IID=\&potID=5\&rSoft

WareName $=\&$ search $=\&$ groupby $=$ pog $\cdot$ pogHeading \&orderby $=$ pog $\cdot \operatorname{pog} I D \& c h a r t t y p e=$ ie $\&$ width $=600$

\&height=300\&caption=Recorded $\% 20$ Preservation\%20Policies\%20-\%20Brazil $>$

Uma vez que, grande parte dos repositórios listados neste diretório são provenientes de instituições de ensino, pode-se considerar que estes dados também fazem parte do contexto das bibliotecas universitárias das IFES brasileiras. Considerando que estas bibliotecas, de maneira geral não possuem uma política definida de preservação digital para seus repositórios, subentende-se que tampouco terão ações definidas para se preservar conteúdos de suas mídias sociais.

Há pesquisas que consideram que por falta de produção de políticas específicas para preservação digital de conteúdos de mídias sociais corremos o risco de entrar em uma nova era de escuridão por falta de capacidade de recuperar essas informações (JEFFREY, 2012). Por conta disso, pesquisadores nas áreas de ciências sociais, história, arqueologia, entre outros, não teriam condições materiais de reconstituir as formas de sociabilidade que se produziram nesses espaços digitais e nem de recuperar objetos, tais como vídeos, fotografias, imagens, gráficos, entre outros, que são parte fundamental de estratégias metodológicas para a produção de suas pesquisas.

É fundamental a produção de novas estratégias de formação, experimentação e construção de políticas de governança da informação que levem em consideração essa dimensão e possa ofertar soluções de preservação que garantam condições de guarda estratégica desse material. Tem-se notícia de algumas ações nesse sentido e que vale aqui relatar.

No texto que relata a estratégia da política de preservação digital da Biblioteca Britânica para o período de 2013 a 2016 (BRITISH LIBRARY, 2013), estima-se que eles já coletaram em torno de 280 terabytes de conteúdos oriundos da web, sendo que isso 
representa em torno de 11.500 .000 itens coletados. Por conta desse planejamento, já estimavam ampliar sua coleção de sites coletados para 4.8 milhões e chegar a 5 petabytes de conteúdos web coletados por volta de 2020. Percebe-se aqui uma política explícita que menciona estratégias de coleta de conteúdos da web e criação de base de dados que visa garantir a preservação e recuperação desses conteúdos.

Outra estratégia que vale mencionar neste artigo é da Digital Preservation Coalition (2015), uma coalização de instituições internacionais interessadas na preservação digital, que realizou um seminário específico sobre a preservação digital de mídias sociais, procurando apresentar tecnologias, metodologias e estratégias de governança no âmbito do governo inglês. O seminário tratou de formas de arquivamento de mídias sociais, problemas de acesso, documentação de dados e tecnologias envolvidas.

São ações como essas, no sentido de produção de políticas de governança e ações de pesquisa e formação, que demonstram ser um debate fundamental para o desenvolvimento de novas estratégias poderão evitar que enfrentemos uma futura era de escuridão por falta de informação.

\section{CONSIDERAÇÕES FINAIS}

A presente pesquisa realizou uma análise descritiva de como se encontra a situação das bibliotecas públicas ligadas a universidades federais no tocante ao uso de mídias sociais experiências na questão da preservação digital de conteúdos oriundos de mídias sociais.

Os resultados demonstram a existência de uma quantidade relevante e bastante representativa das bibliotecas universitárias das IFES que utilizam ferramentas Web $2.0 \mathrm{com}$ enfoque social, sendo a maior adoção do Facebook (43\%) e do Twitter (29\%), seguidos, porém com muito menos intensidade, pelos blogs (7\%). Em se tratando dos tipos de mídias utilizadas, percebe-se também uma relação com a forma como os brasileiros utilizam as mídias sociais. Dados do próprio Facebook (2014) mostram que em torno de $45 \%$ dos brasileiros acessam o Facebook mensalmente. Parece haver uma correspondência aqui entre os usos institucionais das mídias sociais e a forma como as pessoas, de maneira geral, utilizam estas ferramentas colaborativas em suas vidas.

A distribuição de números de seguidores nas mídias sociais das bibliotecas das instituições pesquisadas se mostrou bastante diferenciada. Para avaliar de forma mais detalhada o significado desses resultados, sugere-se futuramente correlacionar o número de estudantes e profissionais de cada instituição e o número de seguidores nas mídias, permitindo entender se esse número se deve ao tamanho dessas instituições ou a políticas específicas de difusão e adoção das mídias. 
Um resultado que também merece destaque diz respeito às estratégias de uso das mídias sociais pelas bibliotecas destas instituições. Identificou-se que apenas $5 \%$ delas utiliza esse meio de comunicação para fazer divulgação dos acervos. Esse dado se mostrou surpreendente, uma vez que no início da pesquisa, pressupunha-se um uso mais efetivo destas mídias com o intuito de informar a comunidade acadêmica sobre materiais informacionais que essas bibliotecas possuem, títulos recém adquiridos, obras raras, exposições, entre outras possíveis estratégias de divulgação acervos. Percebe-se aqui um enorme potencial de produção de novas estratégias que não visem difundir somente informações institucionais, tais como horário de funcionamento, serviços oferecidos, políticas de uso, mas sim aproximar o usuário dos acervos por meio dessas formas inovadoras de divulgação de conteúdo, que são as mídias sociais. O mesmo vale para a periodicidade de postagens, demonstrando que ainda há muitas bibliotecas que não atualizam com frequências os canais, gerando possivelmente desinteresse por parte dos usuários em participar e seguir as mídias sociais, afetando sua credibilidade como um canal oficial de interação social.

Finalizando, por meio da pesquisa bibliográfica e documental realizada, não foram identificadas ações no Brasil, mesmo que piloto, de preservação digital de conteúdos oriundos de mídias sociais. Tal fato sinaliza a incipiência deste tipo de prática nessas bibliotecas ao nível nacional. Há aqui, novamente, um grande potencial de experimentações e produção tanto de novas fontes de informação, bases de dados, como políticas de preservação para conteúdos de ferramentas Web 2.0 uma vez que essas têm se tornado cada vez mais relevantes na sociedade contemporânea. Novamente, aqui tem-se um ponto que pode ser explorado em pesquisas futuras.

Percebem-se novas tendências, mesmo que ainda de forma muito embrionária, no sentido de formação da comunidade acadêmica e da produção de políticas e estratégias de preservação que consideram as mídias sociais e dados da internet de maneira geral. Entendese que mapear essas estratégias e conhecer seus resultados não apenas fornece uma interessante perspectiva para estudos futuros, como também permite que novas experiências possam ser vivenciadas pela comunidade brasileira de pesquisadores e gestores de equipamentos de informação.

Dessa maneira, o que se pode inferir a título de consideração final da pesquisa é que o uso de mídias sociais pelas bibliotecas das IFES brasileiras tem ainda muito a se desenvolver. Talvez fatores ligados à formação dos bibliotecários para uso dessas mídias e a falta de políticas de informação específicas para interação social com os usuários por esse meio possam explicar a situação atual dessas bibliotecas em relação às suas mídias sociais conforme descrito neste estudo. No entanto, faz-se necessária a disponibilização de novos produtos e serviços informacionais por essas bibliotecas que não apenas ampliem seu potencial de conexão e facilitem a participação social de seus usuários em rede, mas também ampliem o potencial de circulação em mídias sociais de conteúdos oriundos de seus acervos e, dessa maneira, possam democratizar ainda mais o acesso à informação. Acredita-se que é 
nessa direção que as bibliotecas universitárias públicas brasileiras devem impulsionar o uso efetivo das mídias sociais para então serem consideradas bibliotecas 2.0.

\section{REFERÊNCIAS}

ACCART, Jean-Philippe. Serviço de referencia: do presencial ao virtual. Brasília. Briquet de Lemos. 2012. 312p.

ALTERMANN, Dennis. Qual a diferença entre redes sociais e mídias sociais. Disponível em http://www.midiatismo.com. br/comunicacao-digital/qual-a-diferenca-entre-redes-sociaise-midias-sociais. Acesso em 23 de maio de 2016.

AMERICAN LIBRARY ASSOCIATION. Library 2.0. Disponível em: < http://www.ala.org/tools/atoz/library-20 >. Acesso em 31 de julho de 2016.

\section{ASSOCIATION FOR LIBRARY COLLECTIONS AND TECHNICAL SERVICES.}

Definitions of Digital Preservation. Disponível em:

<http://www.ala.org/alcts/resources/preserv/2009def>. Acesso: 17 de Set. 2016.

BRASIL, Ministério da Educação. Portal da Rede Federal de Educação Profissional, Científica e Tecnológica. Disponível em: < http://redefederal.mec.gov.br/perguntas-

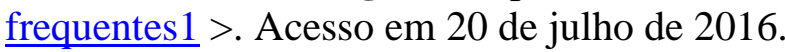

BRASIL, Instituto Nacional de Estudos e Pesquisas Educacionais Anísio Teixeira. Índice Geral de Cursos Avaliados da Instituição - IGC. Disponível em < http://portal.inep.gov.br/educacao-superior/indicadores/indice-geral-de-cursos-igc >. Acesso em 20 de Julho de 2016.

BRITISH LIBRARY, British Library Digital Preservation Strategy. Disponível em: https://www.bl.uk/aboutus/stratpolprog/collectioncare/digitalpreservation/strategy/BL_Digita 1PreservationStrategy_2013-16-external.pdf . Acesso em 21 de setembro de 2016.

CASEY, Michael E.; SAVASTINUK, Laura C. Service for the next-generation library. Library journal, v. 131, n. 1, p. 40-42, 2006.

DINUCCI, Darcy. Design \& New Media: Fragmented Future-Web development faces a process of mitosis, mutation, and natural selection. Print-New York-, v. 53, p. 32-35, 1999.

FACEBOOK. Nosso levantamento mais recente, realizado no último trimestre de 2014, mostra que a presença de brasileiros no Facebook não para de crescer. Disponível em: https://www.facebook.com/business/news/BR-45-da-populacao-brasileira-acessa-oFacebook-pelo-menos-uma-vez-ao-mes. Acesso em 27 de Julho de 2016. 
FERREIRA, Miguel. Introdução à Preservação Digital: conceitos, estratégias e actuais consensos. Guimarães, Portugal: Universidade do Minho, 2006.

JAEGER, Paul T., BERTOT, John Carlo, FLEISCHMANN, Kenneth R. Evolving relationships between information technology and public libraries. In: Public Libraries and the Internet: roles, perspectives and implications. Santa Barbara, California: Libraries Unlimited. 2011. 295p.

JEFFREY, Stuart. A new Digital Dark Age? Collaborative web tools, social media and longterm preservation. World Archeology. Volume 44, número 4. London, United Kingdom. 2012. p. 553-570.

KANE, Laura Townsend. Working in the virtual stacks: the new library and information Science. Chigago. American Library Association Editions. 2011. 167p.

LAVOIE, Brian; DEMPSEY, Lorcan. Thirteen ways of looking at... digital preservation. DLib magazine, v. 10, n. 7/8, 2004.

MEIKLE, James. British Library adds billions of webpages and tweets to archive. The Guardian. 2013. Disponível em: https://www.theguardian.com/technology/2013/apr/05/british-library-archive-webpagestweets . Acesso em: 20 de Jul. 2016.

MON, Lorri. Public Library 2.0: new Technologies, roles and challenges for public libraries. In: BERTOT, John Carlo, JAEGER, Paul T., McClure (Ed.). Public Libraries and the Internet: roles, perspectives and implications. Santa Barbara, California. Libraries Unlimited. 2011. 295p.

O'REILLY, T. "What is Web 2.0?: design patterns and business models for the next generation of software", Disponivel em: $<$ http://oreilly.com/web2/archive/what-is-web-

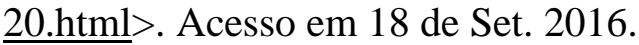

OPEN DOAR. Directory of Open Access Repositories. Disponível em: < http://www.opendoar.org >. Acesso em 21 de Jul. de 2016.

THOMAZ, Guilherme Mendes. Processo de mineração de conteúdos em mídias sociais para auxílio na gestão de destinos turísticos. 222f. Dissertação (Mestrado em Turismo) Setor de Ciências Humanas, Universidade Federal do Paraná, 2014.

TORRES, Cláudio. A Bíblia do Marketing Digital: tudo o que você queria saber sobre o marketing e publicidade na internet e não tinha a quem perguntar. São Paulo: Novatec, 2009.

TRIPATHI, Manorama; KUMAR, Sunil. Use of Web 2.0 tools in academic libraries: A reconnaissance of the international landscape. The International Information \& Library Review, v. 42, n. 3, p. 195-207, 2010.WOODWARD, Jeannet. The transformed library: ebooks, expertise and evolution. Chigago. American Library Association Editions. 2013. $131 \mathrm{p}$. 

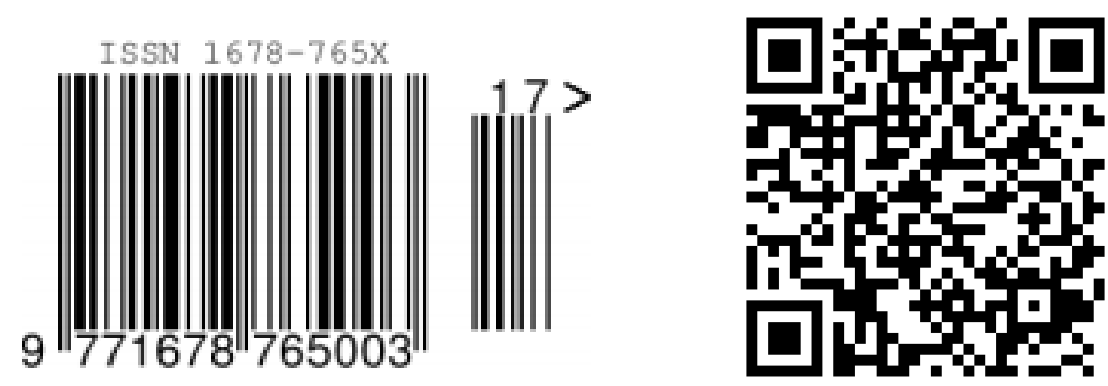